\title{
Impact of occupant behavior on energy use of HVAC system in offices
}

\author{
Zhipeng Deng, ${ }^{1, *}$, Qingyan Chen $^{1}$ \\ ${ }^{1}$ Center for High Performance Buildings (CHPB), School of Mechanical Engineering, Purdue University, 585 Purdue Mall, West \\ Lafayette, IN 47907, USA
}

\begin{abstract}
The current methods for simulating building energy consumption are often inaccurate, and the error could be as large as $150 \%$. Various types of occupant behavior may explain this inaccuracy. Therefore, it is important to identify an approach to estimate the impact of the behaviors on the energy consumption. The present study used EnergyPlus program to simulate the energy consumption of the HVAC system in an office building by implementing a behavioral artificial neural network (ANN) model. The behavioral ANN model calculates the probability of behavior occurrence according to indoor air temperature, relative humidity, clothing level and metabolic rate. The probability was used to predict energy use in 20 offices for one month in winter, spring and summer in 2018, respectively. Measured energy data from the offices were used to validate the simulated results. When a behavioral artificial neural network (ANN) model was implemented in the energy simulation, the difference between the simulated results and the measured data was less than $13 \%$. Energy simulation using constant thermostat set point without considering occupant behavior was not accurate. Our further simulations found that adjustment of thermostat set point and clothing level by occupants could lead to $25 \%$ and $15 \%$ energy use variation in interior offices and exterior offices, respectively.
\end{abstract}

\section{Introduction}

In the United States, $41 \%$ of primary energy consumption occurs in buildings, mainly for maintaining a comfortable and healthy indoor environment. Current methods for simulating building energy consumption are often inaccurate, with error ranging from $150 \%$ to $250 \%$ [1]. A possible reason for the discrepancy could be from various occupant behaviors in the buildings. Therefore, it is important to identify an approach to estimate the impact of the behaviors on the energy consumption.

The existing methods for exploring the effect of occupant behaviors on energy consumption and thermal comfort mostly based on surveys and numerical simulations. For example, Fabi et al. [2] studied the influence of thermostat setting point and window opening on indoor environmental quality and heating demand in residential buildings by using questionnaire surveys and logistic regression. Sun et al. [3] simulated numerically the impact of occupant behaviors on energy savings. Zhao et al. [4] used data mining and numerical simulations to identify the effect of occupant behaviors and schedules on office energy consumption. However, the questionnaires may not record all the information and the numerical simulations may not include all the information for producing accurate results.

A survey on occupant modeling approaches in building simulations [5] showed that $66 \%$ of the researchers modeled the thermostat set point as a daily schedule, while another $16 \%$ used a constant for the entire year. Very few researchers have explicitly acknowledged the occupants' interaction with the thermostats. Some previous studies tried to predict the energy consumption in commercial and residential buildings with various occupant behavior models, such as linear regression model [6], statistical model [7] and stochastic model [8]. However, a review paper [9] pointed out the oversimplifications used in the existing behavior models for energy simulation. At present, very few studies have used comfort-related occupant behavior models for energy simulation [10]. Therefore, the purpose of this study is to investigate the impact of occupant behavior on the energy use of HVAC systems with the use of an appropriate behavioral model.

\section{Methods}

To measure and simulate the energy use of the HVAC systems and study the impact of occupant behaviors on HVAC energy use, this investigation first collected data in 20 offices at Ray W. Herrick Laboratories (HLAB) building, Purdue University. We used the building automation system (BAS), data loggers and questionnaires to collect indoor environmental data and behavior data. Subsequently, and EnergyPlus program to simulate the energy consumption by the HVAC system. We validated the simulation results with the

\footnotetext{
* Corresponding author: deng132@purdue.edu
} 
corresponding measured data. Finally, we implemented the behavioral ANN model [11] into energy simulation program to simulate the impact of occupant behaviors on building energy use.

\subsection{Data collection in the HLAB building}

This investigation collected data from the HVAC systems in the 20 offices in the HLAB building at Purdue University. A half of the offices were multi-occupant student offices, and the rest were single-occupant faculty offices. Fig. 1 shows that the offices for data collection were located on the first floor and second floor of the three-story building. Eight offices located in the exterior zone and others located in the interior zone. The area of the offices was from $12.9 \mathrm{~m}^{2}$ to $21.0 \mathrm{~m}^{2}$. The height of the ceiling was $3.05 \mathrm{~m}$. The HLAB building used a variable air volume (VAV) system for heating and cooling. Each office had an independent VAV box and a thermostat (Siemens 544-760A) that enabled the building automation system (BAS) to control the air temperature in the room. The occupants could adjust the thermostat set point within the range of $18.3^{\circ} \mathrm{C}$ to $26.7^{\circ} \mathrm{C}$. In the heating mode, the hot water valve opened, and the air from the air handling unit could be heated by the reheat coil in the VAV boxes. There was a damper in each VAV box to control the supply airflow rate. (a)

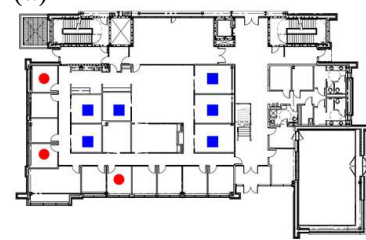

Multi-occupant offices (b)

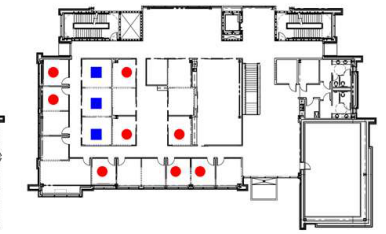

Single-occupant offices
Fig. 1. Layout of (a) the first floor and (b) the second floor of the HLAB building.

This investigation recorded the supply air temperatures, thermostat set points, damper positions, and room occupancies every five minutes. The lights in each office included ultrasonic and passive infrared sensors (Lutron LOS-CDT 500WH) on the ceiling. The lighting on/off status could signify whether or not the offices were occupied. There were temperature sensors (Siemens QAM2030.010) inside the diffusers in each office to monitor the supply air temperature, which was $43.3 \pm 5.5$ ${ }^{\circ} \mathrm{C}$ for heating and $15.5 \pm 2.8^{\circ} \mathrm{C}$ for cooling. We used data loggers (Sper Scientific 800049) in each office to collect the room air temperature and $\mathrm{CO}_{2}$ concentration data.

We also used a questionnaire to collect the seven-scale thermal sensation ( -3 for cold, -2 for cool, -1 for slightly cool, 0 for neutral, +1 for slightly warm, +2 for warm, and +3 for hot), clothing level from the occupants when they were inside the offices, and when they adjusted the thermostat set points and clothing levels. The time when the occupants arrived at and left the office was also recorded.

Note that all data collection in this study was approved by Purdue University with Institutional Review Board Protocol \#1704019079.

\subsection{Supply air flow rate calculation}

We calculated the supply airflow rate by using the measured $\mathrm{CO}_{2}$ concentration in each office with a completely mixing assumption. If an office is not occupied, the indoor $\mathrm{CO}_{2}$ concentration follows the equation:

$$
V \frac{d C_{i}}{d t}=\left(C_{0}-C_{i}\right) Q
$$

where $V$ is the room volume, $C_{i}$ is the indoor $\mathrm{CO}_{2}$ concentration, $t$ is time, $C_{0}$ is $\mathrm{CO}_{2}$ concentration of supply air, $Q$ is the supply air flow rate. The $\mathrm{CO}_{2}$ concentration of return air was equaled to that in the indoor space $C_{i}$. By solving Eq. (1), we obtained

$$
Q t=-V \ln \frac{C_{i}-C_{0}}{C_{i, \text { initial }}-C_{0}}
$$

where $C_{i, \text { initial }}$ is the initial indoor $\mathrm{CO}_{2}$ concentration and $-V \ln \frac{C_{i}-C_{0}}{C_{i, j i n i t a l}-C_{0}}$ was proportional to the time $t$. By measuring the indoor $\mathrm{CO}_{2}$ concentration, we can obtain the supply air flow rate, $Q$.

Then the energy used by the HVAC system, $E$, in the offices is

$$
E=C_{p} \rho Q\left(T_{\text {supply }}-T_{\text {room }}\right)
$$

where $C_{p}$ is the specific heat capacity of air, $\rho$ the air density, $T_{\text {supply }}$ the supply air temperature, and $T_{\text {room }}$ the room air temperature.

\subsection{Energy simulation in EnergyPlus}

\subsubsection{Building geometry model and material properties}

This investigation used EnergyPlus (v8.80) to perform energy simulation for the HLAB building. We first constructed the building geometry model by SketchUp software as shown in Fig. 2. The HLAB building had three stories above the ground and a mechanical basement. On the first floor, the lab areas on the back and corner were not simulated. The third floor was simulated as a single space. As shown in Fig. 1, the HLAB building had offices, conference rooms, computer rooms, elevator rooms, stair rooms, mechanical control rooms, bathrooms, and corridors. Since this study focused on the energy use in the offices, other rooms were merged into one space for 
simplifying the simulations. The interior walls between offices were gypsum walls. The interior walls between offices and corridor were glass walls. The doors of the exterior offices and interior offices were wood and glass, respectively. As for the structure and material properties used for the simulations, the structure information was found in the HLAB building construction drawings and documents, while the material properties were from the ASHRAE Handbook - Fundamentals.

(a)

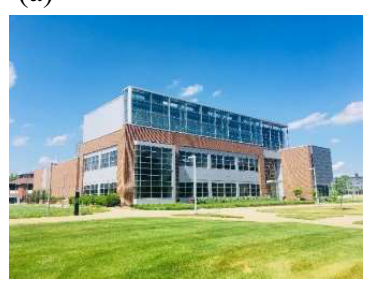

(b)

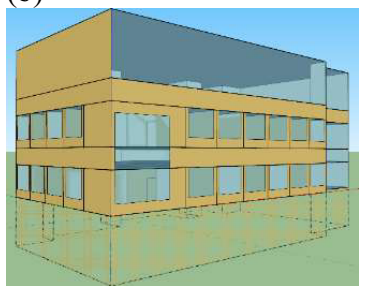

Fig. 2. (a) A photo of the HLAB building and (b) the geometry model of the HLAB building for EnergyPlus simulation

\subsubsection{Outdoor weather data}

To enable comparison of the simulated results with the measured data, our simulations used actual weather data collected at a weather station at the Purdue University Airport, which was $1.5 \mathrm{~km}$ away from the HLAB building. The data were collected hourly and included outdoor air temperature, dew point temperature, relative humidity, air pressure, wind speed, wind direction, etc. As for the solar radiation data, we used the data measured on the roof of the HLAB building from the BAS. The outdoor weather data were collected hourly and organized into the format which was used for EnergyPlus simulation.

\subsubsection{HVAC system settings}

Since each office had an independent thermostat that allowed occupants to adjust the set point temperature, our simulations defined each office as a thermal zone. Other indoor spaces on each floor were merged and simulated as one thermal zone. There were a total of 47 thermal zones in the simulation model. For all the offices in this study, we set the room temperature according to the actual thermostat set point from the BAS at each moment when validating the simulation program. Then we implemented the behavioral ANN model to adjust the thermostat set point for simulating the occupant behaviors. For other offices and the corridors, we set the temperature to be $21.1^{\circ} \mathrm{C}\left(70^{\circ} \mathrm{F}\right)$. This was based on the actual common setting in the HLAB building. There was also a thermostat in the basement controlling the air temperature to be $22.8^{\circ} \mathrm{C}\left(73^{\circ} \mathrm{F}\right)$. Similarly, the air temperature on the third floor was set to be $22.2^{\circ} \mathrm{C}\left(72^{\circ} \mathrm{F}\right)$. The suspended ceiling spaces in each floor were unconditioned.

\subsubsection{Surface temperature and airflow model}

The wall surface temperature and airflow pattern in the offices impacted their energy use. The wall surface temperatures were close to the room air temperatures.
However, the ceiling temperature was $2.7^{\circ} \mathrm{C}\left(5^{\circ} \mathrm{F}\right)$ higher than the floor temperature in heating mode, while $1.1^{\circ} \mathrm{C}$ $\left(2^{\circ} \mathrm{F}\right)$ lower than the floor temperature in cooling mode, because the diffusers were on the ceiling level. Since the surface temperature distribution was not uniform, this temperature difference impacted the convection very much in the energy simulation. Hence, we used a surface mapping method in EnergyPlus to specify the difference between air temperature and surface temperature instead of a well-stirred mixing air model by default.

\subsubsection{Room occupancy, number of occupants, lights, and computers}

Room occupancy would affect the building energy use, such as HVAC system control, lightings, and internal equipment. We used the lighting status from BAS to determine the room occupancy in the single-occupant offices. For the multi-occupant offices, we used questionnaires to collect the arriving and leaving time of each occupant every day. The occupant load was assumed to be $100 \mathrm{~W}$. There were four or eight lamps in singleoccupant exterior offices and multi-occupant interior offices, respectively and each lamp was $32 \mathrm{~W}$. We also assumed that each occupant used one computer (100W) when they worked in the offices.

\subsection{Implementation of the behavior ANN model into energy simulation}

For the building energy simulation, it is necessary to consider the occupant behaviors. When validating the simulation program, we used the actual thermostat set points, occupancy schedules and clothing level information. However, for most building performance simulation in the design phase before the building was built, the actual thermostat set points and occupancy schedule were unknown. This information was also hard to collect in many buildings without BAS. Therefore, we used a behavioral ANN model for building energy simulation to improve the energy simulation results.

In our previous study [11], we built and trained an ANN model to predict the occupant behaviors. The behavioral ANN model could be expressed in the following form:

Behaivor occurence $=\mathbf{w}_{\text {output }}\left\{1+\exp \left[-\left(\mathbf{w}_{\text {hidden }} \mathbf{X}+\mathbf{b}_{\text {hidden }}\right)\right]\right\}^{-1}+b_{\text {output }}$ (4)

where $\mathbf{w}_{\text {output }}$ is the weight matrix in the output layer, $\mathbf{w}_{\text {hidden }}$ is the weight matrix in the hidden layer, $\mathbf{b}_{\text {hidden }}$ is a vector representing bias in the hidden layer, $b_{\text {ouput }}$ is a number representing the bias in the output layer, $\mathbf{X}=\left[T_{\text {air }}, R H, \mathrm{Clo}, \mathrm{Met}\right]^{T}$ is the normalized input parameter vector. There are four input parameters for the behavioral ANN model: air temperature, relative humidity, clothing insulation and metabolic rate. 
This investigation implemented the behavioral ANN model into the energy simulation program. Fig. 3 shows the simulation process with the behavioral ANN model. When the simulation starts, the program first checks whether the office is occupied, since the behavior occurs only when there is an occupant inside the office. If so, the behavioral ANN model calculates the probability of behavior occurrence. With this probability, the program decides whether or not to adjust the thermostat set point. The differences between the single-occupant and multioccupant offices lie in two aspects. First, our previous study [11] demonstrated that behavior occurrence in response to a feeling of discomfort was different in multioccupant offices than in single-occupant offices. The reason for the difference was the compromise that took place among multiple occupants. Second, in singleoccupant offices, the occupants always adjusted the thermostat set point when they felt uncomfortable. While occupants could adjust the thermostat set point or their clothing level in multi-occupant offices, clothing adjustment would impact the thermal comfort of the occupants but not the building energy use.

(a)

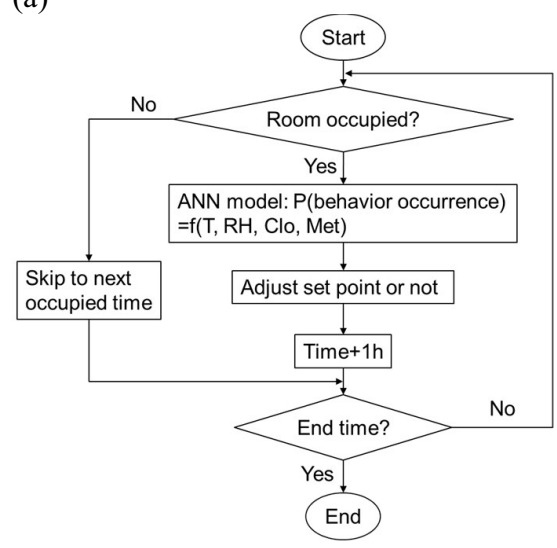

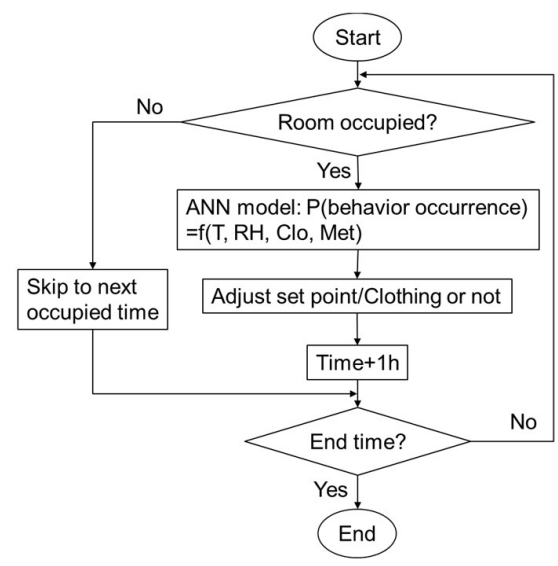

Fig. 3. Simulation process with implementing the behavioral ANN model in energy simulation in (a) single-occupant offices and (b) multi-occupant offices.

\section{Results}

\subsection{Validation of energy simulation program}

We first validated the energy simulation program with energy use data measured in the HLAB building for a onemonth period in three seasons in 2018. The simulation time for winter was from Feb $9^{\text {th }}$ to Mar $9^{\text {th }}, 2018$, spring from March $12^{\text {th }}$ to April $12^{\text {th }}, 2018$ and summer from June $9^{\text {th }}$ to July $9^{\text {th }}, 2018$. Fig. 4 shows the outdoor temperature from January to July in 2018 in West Lafayette. The mean outdoor temperature was $-0.5^{\circ} \mathrm{C}$, $5.2^{\circ} \mathrm{C}$ and $23.4^{\circ} \mathrm{C}$ in the three seasons, respectively.

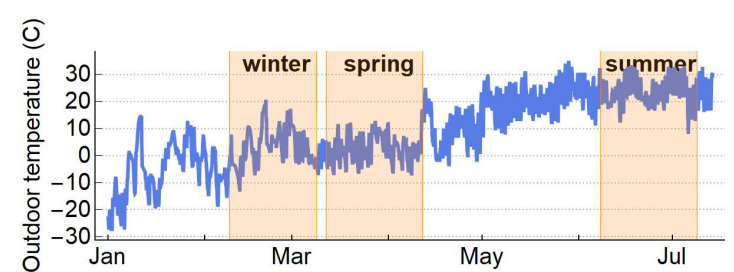

Fig. 4. Outdoor temperature from January to October in 2018

Fig. 5 compares the simulated and measured energy use in all the offices in the three seasons. On March $7^{\text {th }}$ the HVAC control system for all the offices failed so that the heating energy was very high and cooling energy use was zero. Except that day, Table 1 shows the maximum error was $14 \%$ among different seasons. The errors may have arisen from many factors such as door opening. In the simulations we assumed that the office door was closed, but this may not have been the case. If the door was opened, the measured energy use in the office would have increased because of infiltration.

(a)

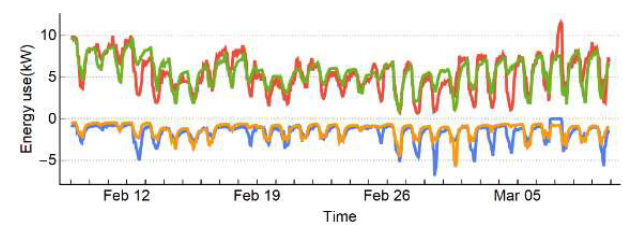


(b)

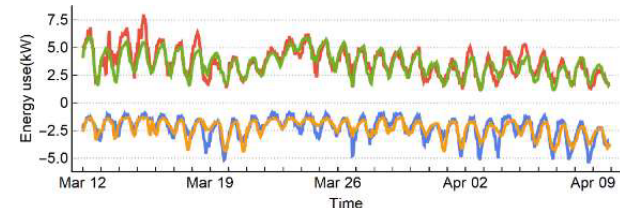

(c)

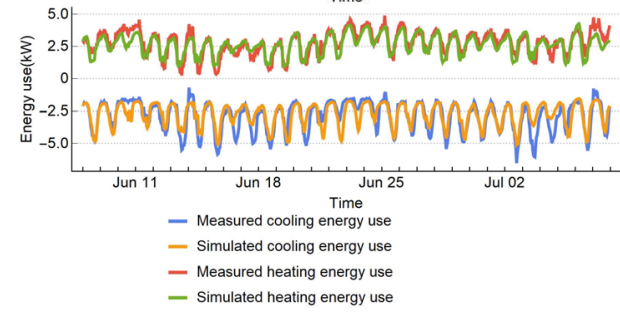

Fig. 5. Comparison between simulated and measured energy use in all the offices for one month in (a) winter, (b) spring, and (c) summer.

Table 1. Comparison between simulated and measured energy use in all the offices for one month in different seasons.

\begin{tabular}{|l|l|l|l|}
\hline & Winter & Spring & Summer \\
\hline $\begin{array}{l}\text { Measured heating } \\
\text { energy use (kWh) }\end{array}$ & 3396 & 2833 & 2102 \\
\hline $\begin{array}{l}\text { Simulated heating } \\
\text { energy use (kWh) }\end{array}$ & 3177 & 2719 & 1945 \\
\hline Error & $6.40 \%$ & $4 \%$ & $7 \%$ \\
\hline $\begin{array}{l}\text { Measured cooling } \\
\text { energy use (kWh) }\end{array}$ & 857 & 2261 & 2726 \\
\hline $\begin{array}{l}\text { Simulated cooling } \\
\text { energy use (kWh) }\end{array}$ & 736 & 2041 & 2565 \\
\hline Error & $14 \%$ & $9.70 \%$ & $6 \%$ \\
\hline
\end{tabular}

\subsection{Comparison of the simulated energy use between} single- and multi-occupant offices

After validating the EnergyPlus program, we ran the simulations with the behavioral ANN model and compared the simulated results with the measured energy use. Because of the randomness of the occupant behavior, every simulated result with the behavioral ANN model was different. If we had run only a few simulations, they may not have been representative and could not have covered all the possible ranges. Therefore, we ran the simulations with the behavioral ANN model for 200 times. We used a box whisker chart to display the simulated results, since this type of chart can illustrate the mean and standard deviations (SD) for various simulations. Figs. 6 and 7 show the energy use of the 11 offices in the interior zone and the nine offices in the exterior zone for two days in winter, respectively. The white lines represent the mean. The boxes represent the mean plus and minus standard deviation. The whiskers represent the upper and lower bounds. As the figures show, the simulated results with the behavioral ANN model match well the measured data. The simulated results with the behavioral ANN model also indicate the variation of energy use due to the behaviors. At every moment, the variation of energy use could be $1 \mathrm{~kW}$ and $0.5 \mathrm{~kW}$ for heating and cooling in interior zone, respectively, and $0.5 \mathrm{~kW}$ and $0.2 \mathrm{~kW}$ in exterior zone, respectively. These variations accounted for more than $25 \%$ and $15 \%$ of total energy consumption in the interior and exterior zone, respectively. The variation in the interior zone was larger than that in the exterior zone because the surrounding temperature of the interior offices was much higher (corridor temperature was around $21.1^{\circ} \mathrm{C}\left(70^{\circ} \mathrm{F}\right)$ ) than the exterior offices (outdoor air temperature was less than $4.4^{\circ} \mathrm{C}\left(40^{\circ} \mathrm{F}\right)$ in winter). As a result, the relative change of adjusting thermostat set point for $0.56^{\circ} \mathrm{C}\left(1^{\circ} \mathrm{F}\right)$ in the interior zone was much larger than in the exterior zone. Therefore, the impact of adjusting thermostat set point behavior on energy use in interior offices is larger than that in exterior offices.

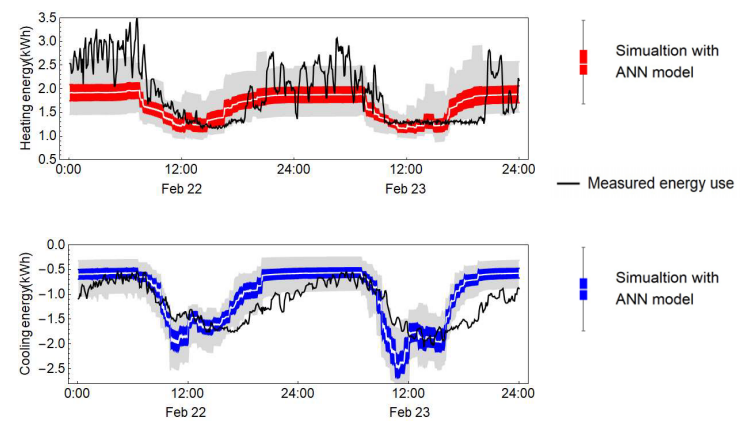

Fig. 6. Energy use of the 11 offices in interior zone for two days in winter

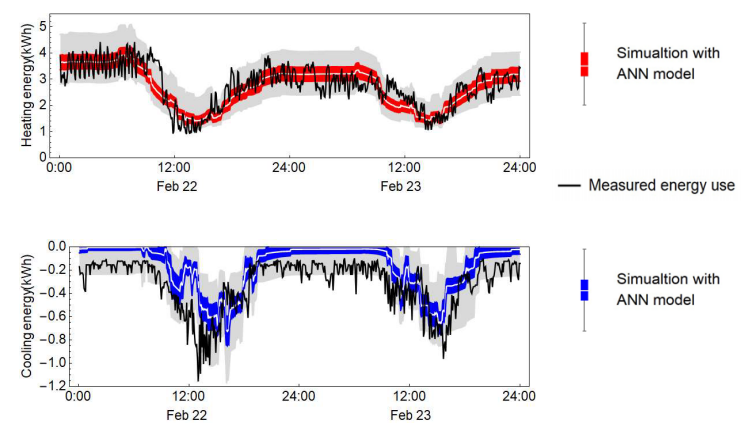

Fig. 7. Energy use of the nine offices in interior zone for two days in winter

\subsection{Comparison of the simulated energy use with different behavior models}

Fig. 8 compared the simulations using the behavioral ANN model with those using only constant temperature set point, using the actual behavior and the measured case 
for two days in winter and summer. The simulation case with constant thermostat set point used $22.8^{\circ} \mathrm{C}\left(73^{\circ} \mathrm{F}\right)$. The results of the simulated case using actual behavior were closest to the measured one. The simulations used the behavioral ANN model, constant temperature set point, and actual behavior. The results that were simulated with the use of actual occupant behavior were closest to the measured data, which is completely understandable. The simulations with the behavioral ANN model also performed well. Most of the time, the measured energy fluctuated within the lower and upper bounds predicted by the behavioral ANN model. However, the simulation with constant thermostat set point exhibited a large discrepancy with the experimental data. The relative error was as large as $30 \%$. The reason was that some occupants set the thermostat set point much higher or lower than $22.8^{\circ} \mathrm{C}$ $\left(73^{\circ} \mathrm{F}\right)$ in order to feel comfortable. They did not reset the thermostat when they left the office, and this behavior wasted considerable energy. That is why the measured energy use was higher than the predicted energy using constant thermostat set point, to some extent.

(a)
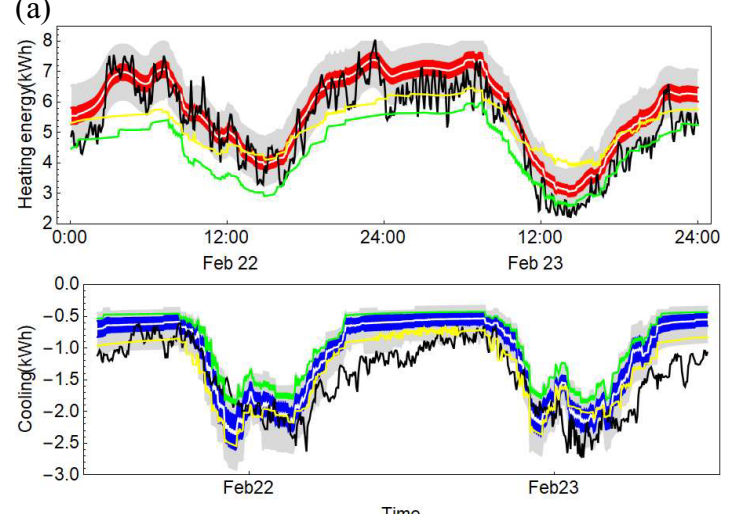

(b)
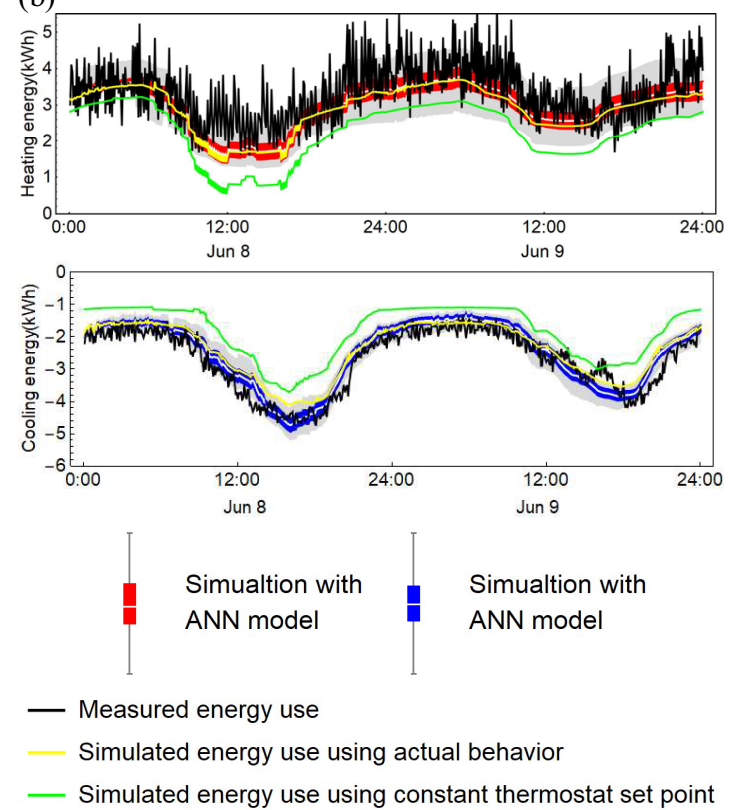

\footnotetext{
- Simulated energy use using actual behavior

- Simulated energy use using constant thermostat set poin
}

- Measured energy use

Fig. 8. Comparison of energy use of all the offices for two days in (a) winter and (b) summer
Fig. 9 summarizes the measured energy use simulated by using actual behavior and the behavioral ANN model for one month in the winter, spring, and summer, respectively. In the winter and spring, the heating energy was higher than cooling energy, but vice versa in the summer. Furthermore, in the winter and shoulder seasons the variation in energy use due to occupant behavior was greater for cooling than for heating. Meanwhile, the variation in energy use in the summer was smaller than in other seasons. This difference occurred because heating energy in the summer was mostly used when the interior offices were unoccupied and in the exterior offices at night. In these cases, occupant behavior seldom affected the energy use of the HVAC system.

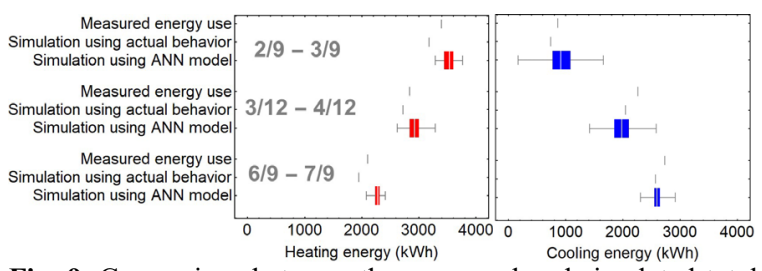

Fig. 9. Comparison between the measured and simulated total energy use in the 20 offices for one month in the winter, spring and summer.

\section{Discussion}

In this study, we used the behavioral ANN models to simulate the occupant behaviors and compared with actual energy use. We used questionnaires to record selfreported behavior and clothing level. However, sometimes the occupants may have forgotten to record the data, which would have affected the behavioral modeling and simulated energy results.

The actual heating energy use fluctuated a lot in summer as shown in Fig. 8. We checked the heat exchanger in the HLAB building to find out the reason. Although the water temperature set point was $54.4^{\circ} \mathrm{C}\left(130^{\circ} \mathrm{F}\right)$, the supply water temperature could sometime be as high as $76.7^{\circ} \mathrm{C}$ $\left(170^{\circ} \mathrm{F}\right)$ and fluctuated.

Due to the randomness of the occupant behaviors, every simulation result was different. Therefore, we had to run the simulation with the behavioral ANN model for multiple times. The simulated results of 200 times and 500 times had very small difference. Therefore, 200 simulations should be used with the behavioral ANN model.

\section{Conclusions}

In this study, we validated the energy simulation program and compared the simulated results with the behavioral ANN model with the HLAB building data. This investigation led to the following conclusions:

(1) The energy simulation results were validated for the HLAB building for one month in winter, spring and summer in 2018 , and the error was less than $14 \%$. 
(2) 2)The simulated energy consumption using the behavioral ANN model exhibited variation as a result of occupant behavior in the HLAB offices. The variation was $25 \%$ in interior offices and $15 \%$ in exterior offices.

(3) The implementation of the behavior ANN model into energy simulation program could improve the simulation results. The simulation with the behavioral ANN model performed as well as using actual behavior, and better than the case using constant thermostat set point.

The authors would like to thank Dr. Orkan Kurtulus of the Center for High Performance Buildings at Purdue University for his assistance in setting the BAS in the HLAB building. We would also like to thank all the occupants of the offices for their participation and assistance in obtaining the data reported in this study. The research presented in this paper was supported by the Center for High Performance Buildings at Purdue University.

\section{References}

1. P. De Wilde, The gap between predicted and measured energy performance of buildings: A framework for investigation. AUTOMAT. CONSTR. 40-49, 41 (2014).

2. V. Fabi, R. V. Andersen, and S. P. Corgnati, Influence of occupant's heating set-point preferences on indoor environmental quality and heating demand in residential buildings. HVAC\&R RES 635-645, 19.5 (2013).

3. K. Sun, T. Hong, A framework for quantifying the impact of occupant behavior on energy savings of energy conservation measures. ENERG. BUILDINGS., 383-396, 146 (2017).

4. J. Zhao, B. Lasternas, K. P. Lam, R. Yun, V. Loftness, Occupant behavior and schedule modeling for building energy simulation through office appliance power consumption data mining. ENERG. BUILDINGS., 341-355, 82(2014).

5. W. O'Brien, I. Gaetani, S. Gilani, S. Carlucci, P. Hoes, J. Hensen, International survey on current occupant modelling approaches in building performance simulation. J BUILD PERFORM SIMU 653-671, 10 (2017).

6. R. V. Andersen, B. W. Olesen, J. Toftum. Modelling occupants' heating set-point prefferences. Building Simulation Conference 14-16, (2011).

7. J. Pfafferott, S. Herkel. Statistical simulation of user behaviour in low-energy office buildings. Solar Energy 676-682, 81.5 (2007).

8. H. Jang, J. Kang. A stochastic model of integrating occupant behaviour into energy simulation with respect to actual energy consumption in high-rise apartment buildings. ENERG. BUILDINGS, 205216, 121 (2016).

9. T. Hong, S. C. Taylor-Lange, S. D’Oca, Y. Da, S. P. Corgnati. Advances in research and applications of energy-related occupant behavior in buildings. ENERG. BUILDINGS. 694-702, 116 (2016).
10. A. Paone, J. P. Bacher. The Impact of building occupant behavior on energy efficiency and methods to influence it: A review of the state of the art. Energies 953, 11.4 (2018).

11. Z. Deng, Q. Chen. Artificial neural network models using thermal sensations and occupants' behavior for predicting thermal comfort. ENERG. BUILDINGS. 587-602, 174 (2018).

12. Standard, ASHRAE. 55 (2013). 